\title{
Oxidation of Alkynes via Catalytic Metal-Vinylidenes
}

\author{
Andrea Álvarez-Pérez \\ Carlos Saá* \\ Jesús A. Varela* \\ Centro Singular de Investigación en Química Biolóxica e \\ Materiais Moleculares (CiQUS), Departamento de Química \\ Orgánica, Universidade de Santiago de Compostela, 15782 \\ Santiago de Compostela, Spain \\ jesus.varela@usc.es \\ carlos.saa@usc.es
}

Click here to insert a dedication

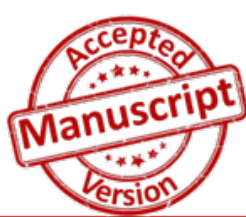

This article may be used for non-commercial purposes in accordance with Thieme Terms and Conditions for self-archiving.

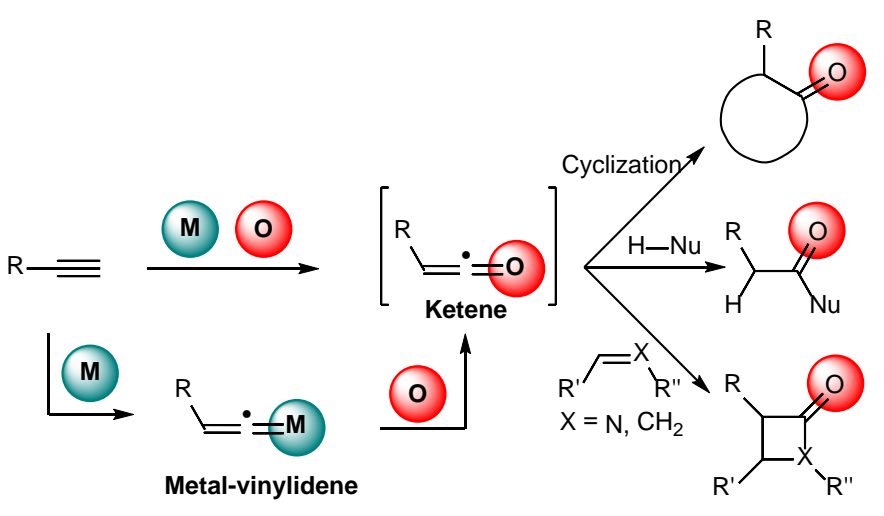

followed by 1,2-hydrogen shift has been proposed (c, Scheme 1). ${ }^{4 c-h, 5 d, 7}$

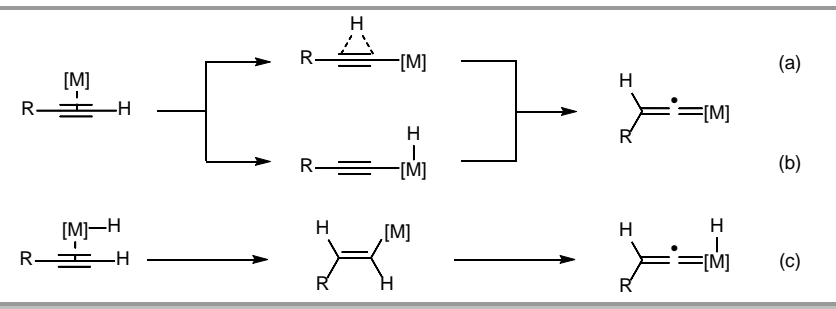

Scheme 1 General mechanistic pathways for the formation of metalvinylidenes from terminal alkynes

A more unusual transformation is the formation of vinylidenes from internal alkynes and examples for trialkylsilyl, trimethylstannane, ${ }^{9}$ alkylthiol ${ }^{10}$ and iodo ${ }^{11}$ substituted alkynes have been described. For the case of internal substituted alkynes with acyl and aryl groups, the order of migratory efficiency was stablished as: $\quad \mathrm{CO}_{2} \mathrm{Et}>p-\mathrm{CO}_{2} \mathrm{EtC}_{6} \mathrm{H}_{4}>p-\mathrm{ClC}_{6} \mathrm{H}_{4}>\mathrm{Ph}>p$ $\mathrm{MeC}_{6} \mathrm{H}_{4} \mathrm{Me}>p-\mathrm{OMeC}_{6} \mathrm{H}_{4}{ }^{12}$

The most relevant transformations in which vinylidenes are involved, such as nucleophilic additions to the electrophilic coordinated $\mathrm{C}_{\alpha}$, intramolecular cyclizations or pericyclic reactions, arise from their electronic properties which determine that their $\mathrm{C}_{\alpha}$ is an electrophilic carbon while $\mathrm{C}_{\beta}$ is nucleophilic, have been extensively reviewed. ${ }^{13}$

Furthermore, when alkynes are treated with transition metals under oxidative conditions, formation of two different intermediates are postulated depending on the initial coordination-type between the metal and the triple bond (Scheme 2). Should the coordination occurs in a $\eta^{2}$-binding mode, an $\alpha$-oxocarbenic species would be formed by oxygen transfer to the alkyne (a, Scheme 2). ${ }^{14}$ Should a metal-vinylidene species is initially formed, a ketene ${ }^{15}$ intermediate would be the oxidation product, even though this process is still under investigation due to the high reactivity and the absence of spectroscopic data of the reaction intermediates $(b$, Scheme 2$) .{ }^{16}$ 


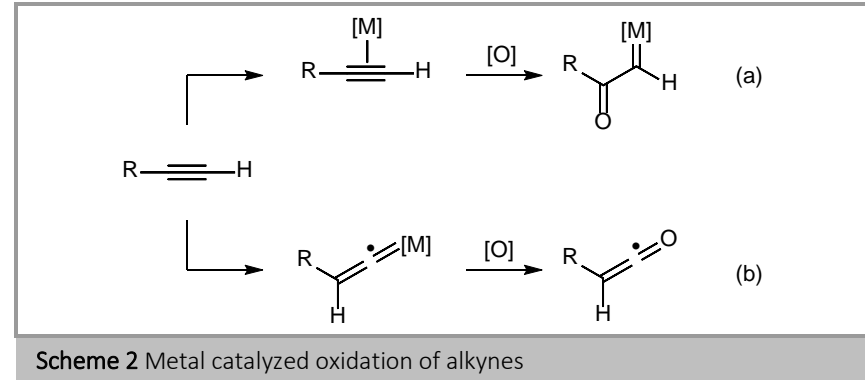

In this short review we will focus in the recent advances of the metal-catalyzed oxidation of alkynes via ketene intermediates by oxidation of the initially formed metal-vinylidenes.

\section{Oxidation of Metal-Vinylidenes with Internal Oxidants}

The first chapter of this review covers the metal-catalyzed oxidation of alkynes via metal-vinylidene complexes in which the oxidant is embedded into the alkyne moiety.

\subsection{Intramolecular Reactions}

\subsubsection{Cyclizations}

The rearrangement of (o-ethynyl)phenyl epoxides to 3substituted-2-naphthols using $\left[\mathrm{TpRu}\left(\mathrm{PPh}_{3}\right)\left(\mathrm{CH}_{3} \mathrm{CN}\right)_{2}\right] \mathrm{PF}_{6}$ as catalyst was described in 2004 (Scheme 3). ${ }^{17}$ The proposed mechanism for this transformation involves the initial generation of the vinylidene-ruthenium species $\mathbf{I}$, as supported by deuterium-labeling experiments, followed by intramolecular electrocyclization triggered by the attack of the epoxide to the electrophilic carbon of the vinylidene to yield the sevenmembered ether II. This species is strongly stabilized by cationic delocalization as shown in the resonant structure II'. Subsequent cleavage of cyclic ether gives rise to the key ruthenium- $\pi$-ketene species III in equilibrium with its isomeric species IV. The formation of ruthenium- $\pi$-ketene species III is firmly supported by the formation of its ester derivatives when alcohols were used as solvents instead of toluene. Finally, the ketene undergoes a 6endo-dig electrocyclization to form the six-membered ketone species $\mathbf{V}$ which, after deprotonation and reprotonation, gives the naphthol derivatives with regeneration of active ruthenium species.

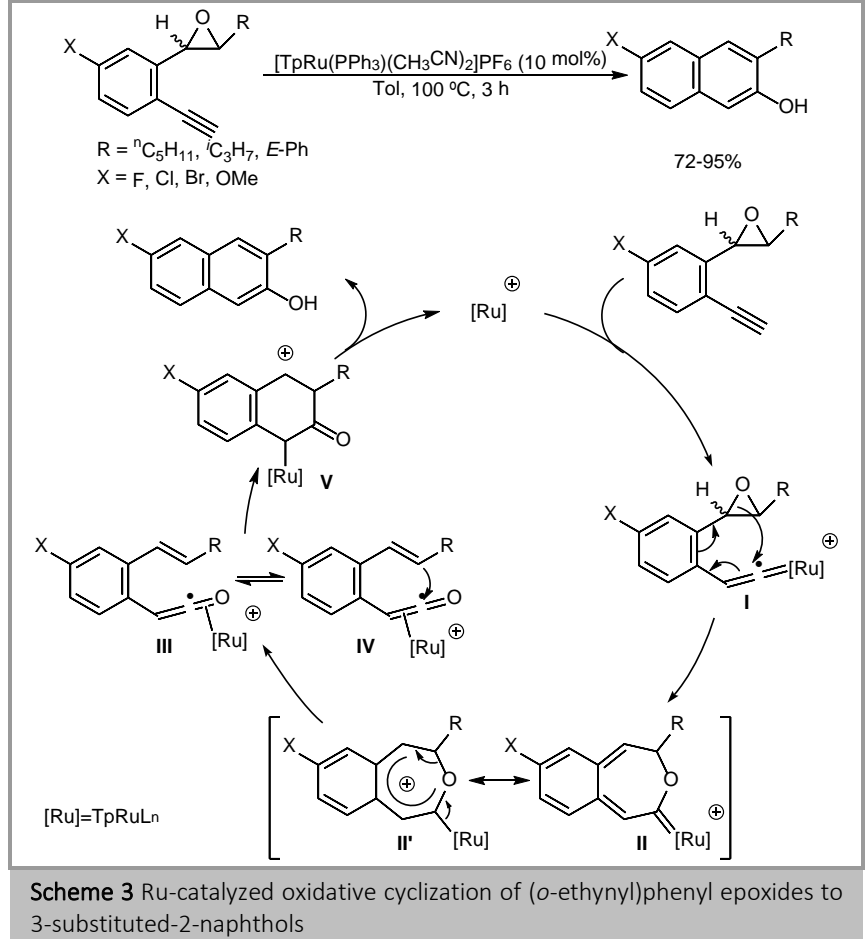

When trisubstituted (o-ethynyl)phenyl epoxides were used, ketene intermediate IV undergo a more favorable 5-endo-dig electrocyclization to afford species VI which evolve to 1alkylidene-2-indanones (Scheme 4$) \cdot{ }^{17}$

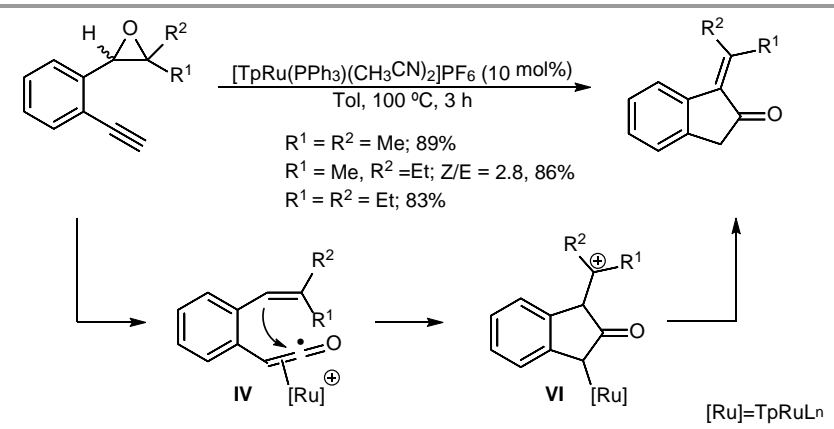

Scheme 4 Ru-catalyzed oxidative cyclization of trisubstituted (o-ethynyl)phenyl epoxides to 1 -alkylidene-2-indanones

As shown in the previous examples, the nature of the substituents on the epoxide moiety is crucial for the chemoselectivity of the cyclization since it relies on the cationic charge location. Thus, when (o-ethynylphenyl)-2-alkyl-2-aryl epoxides are treated with $\left[\mathrm{TpRu}\left(\mathrm{PPh}_{3}\right)\left(\mathrm{CH}_{3} \mathrm{CN}\right)_{2}\right] \mathrm{PF}_{6}$ in hot toluene, 1-aryl-2-alkyl-1Hindene species are obtained in good yields (Scheme 5).18 The proposed mechanism for this transformation involves the formation of the ruthenium-acyl species VII from the rutheniumvinylidene species I instead the typical Ru-ketene species. Ketene intermediates were discarded as intermediates in this case because the formation of esters derived from its trapping with isobutyl alcohol, when it was used as solvent, were not observed. In this case, an equilibrium between species II and VII was proposed because of the stability of the tertiary benzylic cation formed. Subsequently, ruthenium-acyl species VIII would be formed via intramolecular attack of ruthenium at the tertiary cationic center. Then, seven-membered acyl species VIII would undergo decarbonylation to give ruthenium-cyclohexadiene 
intermediates IX which, after reductive elimination, would generate cyclopentadiene $\mathbf{X}$. The addition of $\mathrm{H}^{+}$or $\mathrm{Ru}^{+}$species to $\mathbf{X}$ is expected to yield benzylic cations $\mathbf{X I}$. The $\pi$-conjugation promotes 1,2-phenyl migration to give stable tertiary cation XII which finally evolves to indene products. No direct evidence for the formation of ruthenium-ketene intermediates was observed, but the loss of $\mathrm{CO}$ would indicate most likely the generation of $\mathrm{Ru}$ (IV)-acyl intermediates.

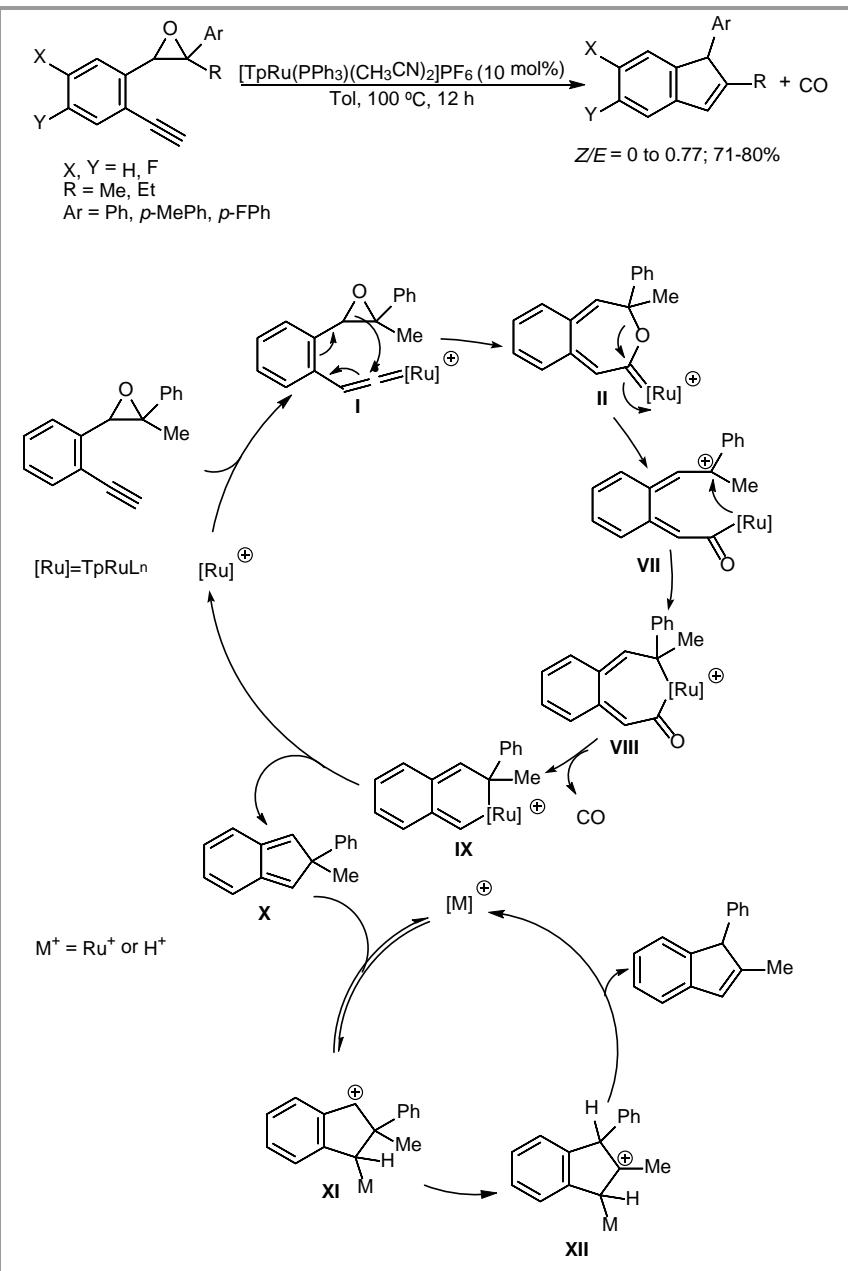

Scheme 5 Ru-catalyzed cyclization of (o-ethynylphenyl)-2-alkyl-2-aryl epoxides to indenes through Ru-acyl intermediates with loss of CO

Further investigations on the influence of the skeleton of the alkynylepoxides in the chemoselectivity of the reaction were carried out using 1,2-disubstituted and 1,2,2-trisubstituted epoxides bearing a cis-enynyl chain (Scheme 6). ${ }^{18}$ When 1,2disubstituted lineal epoxides were heated at $100{ }^{\circ} \mathrm{C}$ in toluene in the presence of $\left[\mathrm{TpRu}\left(\mathrm{PPh}_{3}\right)\left(\mathrm{CH}_{3} \mathrm{CN}\right)_{2}\right] \mathrm{PF}_{6}$, naphthol derivatives were obtained, while when 1-(cis-1,3-butenynyl)-2,2-dialkyl epoxides were used, 6,6-disubstituted cyclohexa-2,4-dien-1-ones were achieved in very good yields. In both cases, the reactions using alcohols as solvent gave rise to esters, which indicates that the formation of Ru-ketene intermediate XIII is likely. ${ }^{17}$ Then, a 6-endo-dig cyclization of the terminal alkenyl carbon over the ketene would gave ruthenium- $\pi$-cyclohexadienone species XIV which would afford naphthol or cyclohexa-2,4-dien-1-one depending on the initial substitution on the epoxide moiety.

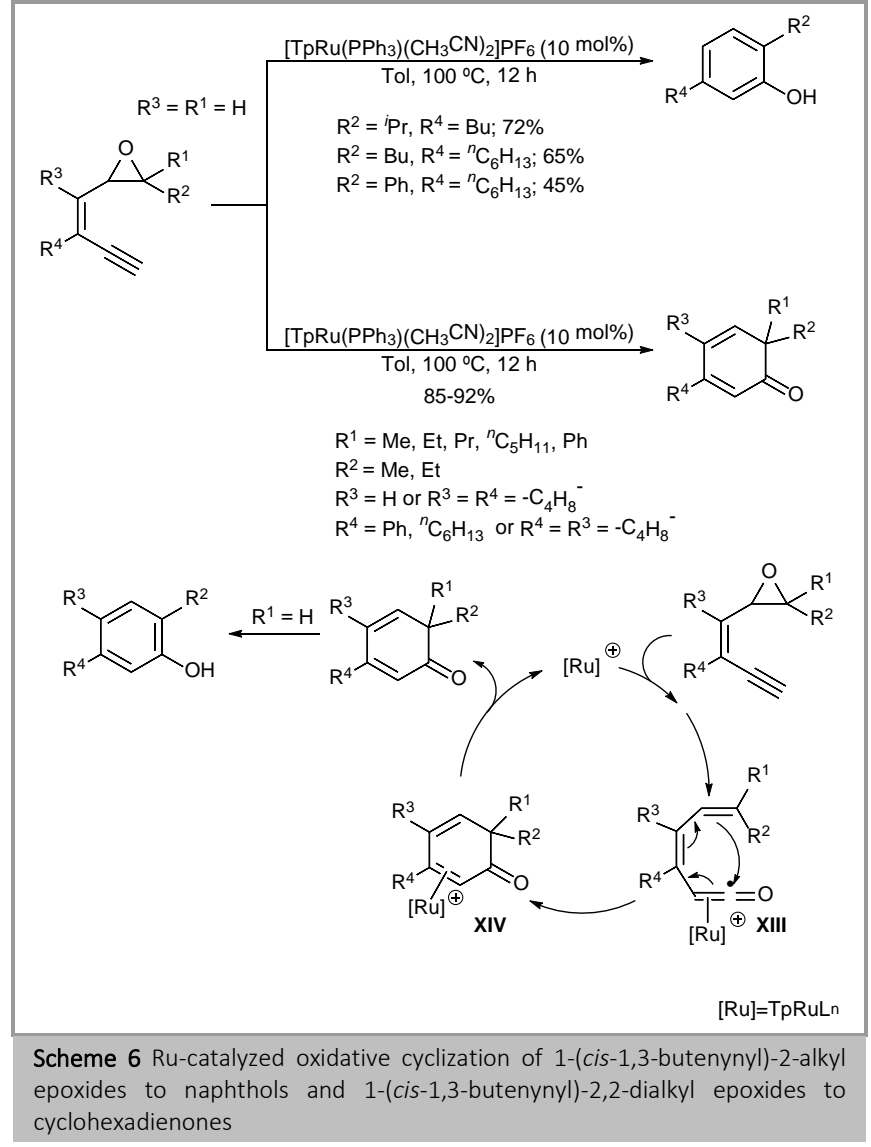

Similar transformation was also found when non-terminal alkynes were used. Polarity of the medium affected the course of the reaction. Heating 1-(2'-iodoethynyl)-2-alkyloxiranes in the presence of $\left[\mathrm{TpRu}\left(\mathrm{PPh}_{3}\right)\left(\mathrm{CH}_{3} \mathrm{CN}\right)_{2}\right] \mathrm{PF}_{6}$ using polar DMF as solvent gave rise to 1-iodo-2-naphthol derivatives while using apolar benzene as solvent 2-iodobenzo[d]oxepines were obtained (Scheme 7).19 The proposed mechanism involves the initial formation of the Ru-2-iodovinylidene species XVI which evolves to 1-iodo-2-naphthol derivatives by a similar mechanism to the one shown in Scheme 3. 


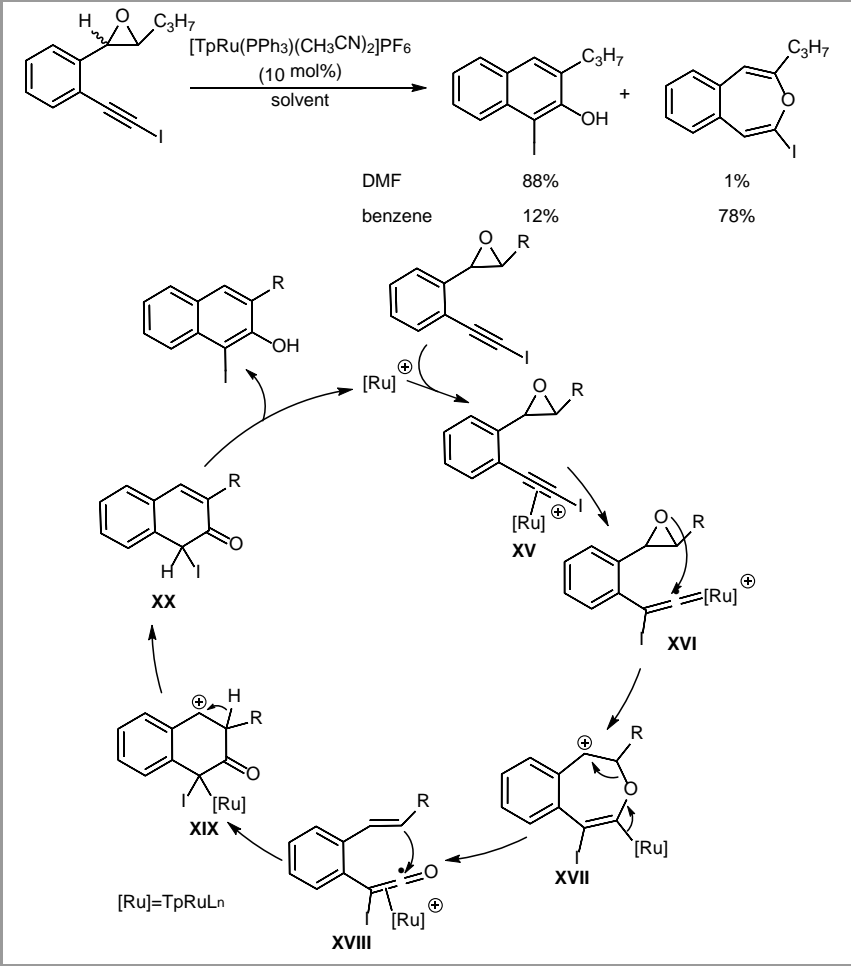

Scheme 7 Ru-catalyzed oxidative cyclization of 1-(2'-iodoethynyl)-2alkyloxiranes to 1-iodo-2-naphthol derivatives

A similar strategy but using nitrones as internal oxidants and $\left[\mathrm{TpRu}\left(\mathrm{PPh}_{3}\right)\left(\mathrm{CH}_{3} \mathrm{CN}\right)_{2}\right] \mathrm{PF}_{6}$ as catalyst allowed the efficient synthesis of $\alpha$-pyridones and 3- $(2 H)$-isoquinolones from 3-en-5ynyl and $o$-alkynylphenyl nitrones (Scheme 8). ${ }^{20}$ The proposed mechanism would involve the formation of the ketene intermediate XXIII by $\mathrm{N}-\mathrm{O}$ bond breaking of the cationic species XXII', a resonant form of XXII which in turn would be generated from a $8 \mathrm{e}-\pi$ electrocyclization of the initially formed $\mathrm{Ru}$ vinylidene species $\mathbf{X X I}$.

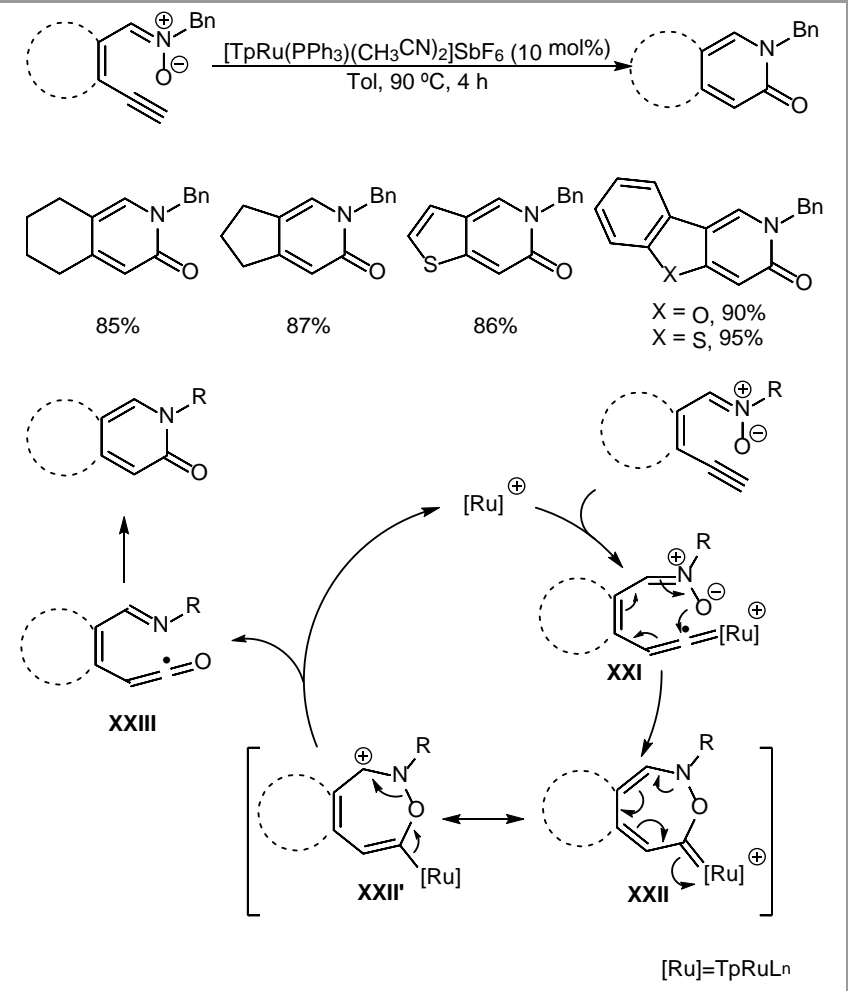

Scheme 8 Ru-catalyzed oxidative cyclization of 3-en-5-ynyl nitrones to $\alpha$ pyridones and mechanistic proposal

\subsection{2 [2+2] Cycloadditions}

A tandem intramolecular process involving a $\mathrm{Ru}(\mathrm{II})$-catalyzed oxidative transformation of terminal alkynes to ketenes by using sulfoxides as internal oxidants followed by a thermal [2+2] cycloaddition with tethered alkenes allowed an easy entry to bicyclic cyclobutanones (Scheme 10). ${ }^{21}$ Neutral Ru(III) and Ru(II) complexes showed no catalytic activity in spite of the well-known ability of $\mathrm{CpRuCl}\left(\mathrm{PPh}_{3}\right)_{2}$ to generate vinylidenes (Table 1, entry 1). By contrast, opening a vacant in the coordination sphere of the metal with the generation of a cationic Ru(II) complex seemed convenient for the reactivity (Table 1, entry 2). However, formation of many secondary products suggested that the generation of ruthenium vinylidenes was not efficient, being necessary the use of an AZARPHOS L1 ligand to improve the yields (Table 1, entry 3). Finally, the use of the synthetically more accessible AZARPHOS L2 ligand allowed the obtention of the cyclobutanones in very good yields (Table 2, entries 4 and 5).

Table 1 Optimization of the Ru-catalyzed oxidative [2+2] cycloaddition of alkynes and alkenes to cyclobutanones

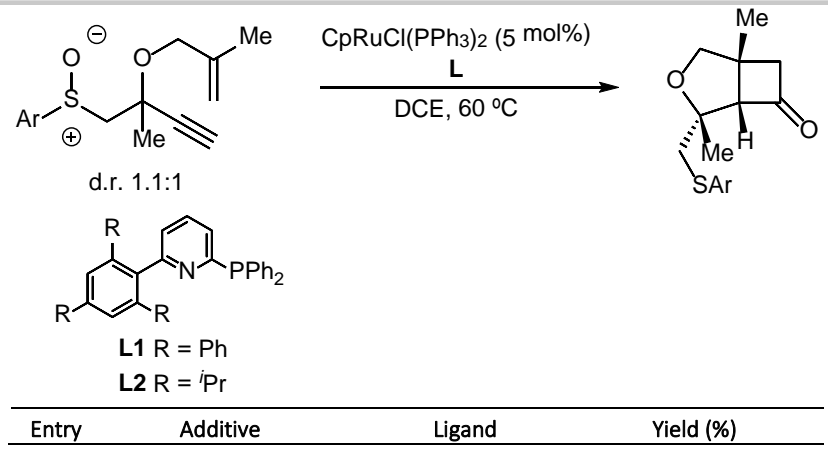




\begin{tabular}{llll}
\hline 1 & none & none & 0 \\
2 & $\mathrm{NaPF}_{6}$ & none & 36 \\
3 & $\mathrm{NaPF}_{6}$ & $\mathrm{~L} 1$ & 81 \\
4 & $\mathrm{NaPF}_{6}$ & $\mathrm{~L} 2$ & 86 \\
5 & $\mathrm{NaBAr}_{4}{ }^{\mathrm{F}}$ & $\mathrm{L} 2$ & 93 \\
\hline
\end{tabular}

The substrate scope of this transformation tolerates mono- and disubstituted alkene units like phenyl and cyclohexene derivatives. Different connecting tethers between the alkene and alkyne functionalities containing cyclohexane and 1,3-dithiane rings are also tolerated (Scheme 9).

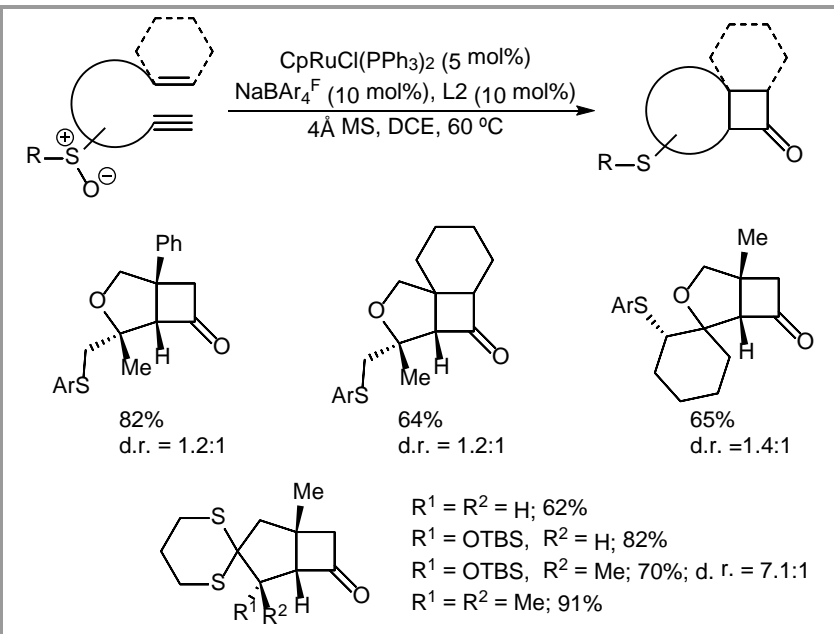

Scheme 9 Scope of the Ru-catalyzed oxidative [2+2] cycloaddition of $\alpha, \omega$ enynes to cyclobutanones

Curiously, the reaction failed when an external sulfoxide was used as oxidant. Thus, when an enynyl sulfide or sulfone was subjected to the reaction conditions under and excess of phenyl methyl sulfoxide no formation of cyclobutanone was observed (Scheme 10).

$$
\begin{aligned}
& \begin{array}{c}
\text { [CpRuCl(PPh } \left.)_{2}\right](5 \mathrm{~mol} \%) \\
\mathrm{CeN}
\end{array} \\
& 0 \% \\
& \mathrm{X}=\mathrm{S} \text {; SM recovery } 60-70 \% \\
& \mathrm{X}=\mathrm{SO}_{2} \text {; SM recovery } 80 \%
\end{aligned}
$$

Scheme 10 Failed attempts of Ru-catalyzed oxidative [2+2] cycloaddition of alkynes and alkenes using external sulfoxide oxidants

The proposed mechanism for the $\mathrm{Ru}(\mathrm{II})$-catalyzed oxidative $[2+2]$ cycloadditions of alkynes and alkenes would involve the the initial formation of Ru-vinylidene species XXIV, oxidation by the sulfoxide to the ketene $\mathbf{X X V}$ and further [2+2] cycloaddition to the cyclobutanone (Scheme 11). Participation of a Rucomplexed ketene could not be ruled out. An alternative mechanism involving an initial [2+2] cycloaddition ${ }^{22}$ between the Ru-vinylidene XXIV and the alkene to Ru-carbene XXVI followed by its intramolecular oxidation could not be discarded, even though the lack of reactivity when external oxidants were used (Scheme 10) argues against this route since intermolecular oxidation of Ru-carbenes to carbonyl groups has been described. ${ }^{23}$

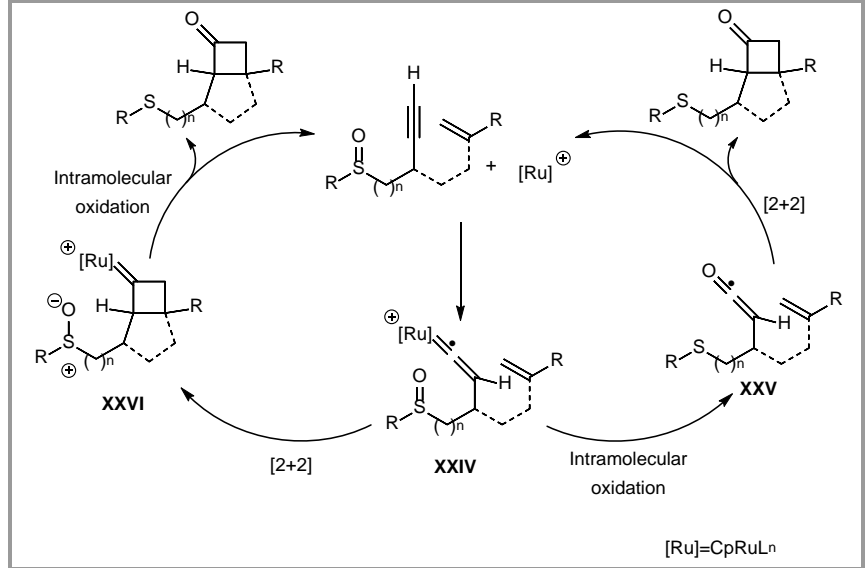

Scheme 11 Alternative mechanistic pathways for the Ru-catalyzed oxidative $[2+2]$ cycloaddition of $\alpha, \omega$-enynes and alkenes to cyclobutanones

\subsection{Intermolecular Reactions}

Other possibility is the participation of two partners in the process, one bearing the alkyne moiety and the internal oxidant and the second one a species that reacts with the ketene intermediate generated in situ by oxidation of the initial metalvinylidene.

\subsubsection{Nucleophilic Additions}

The high electrophilicity of ketenes makes easy its trapping with oxygenated and nitrogenated nucleophiles to afford esters, amides and carboxylic acids. ${ }^{15}$ The generation of these highly reactive intermediates by oxidation of metal-vinylidenes opens new opportunities for direct transformation of alkynes into products derived from the addition of nucleophiles to ketenes.

A first example of the synthesis of esters and amides by reaction of $o$-sulfinyl phenylacetylenes in the presence of oxygenated or nitrogenated nucleophiles using $[\mathrm{RhCl}(\operatorname{cod})]_{2}$ as catalyst and an electron poor phosphine such as $\mathrm{P}\left(4-\mathrm{FC}_{6} \mathrm{H}_{4}\right)_{3}$ was reported in 2013 (Scheme 12). ${ }^{24}$ Conversely, typical Ru(II) catalysts used for the generation of ruthenium vinylidenes gave the products in very low yields.

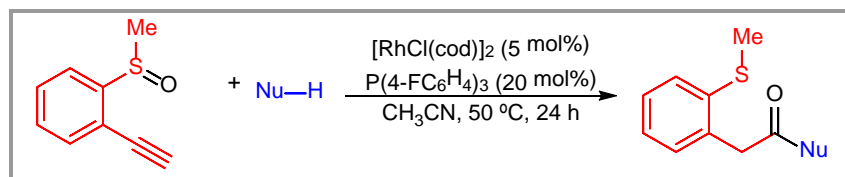

$\mathrm{Nu}-\mathrm{H}=\mathrm{MeOH}, \mathrm{EtOH},{ }^{i} \mathrm{PrOH}, \mathrm{PhOH} ; 45-76 \%$

$\mathrm{Nu}-\mathrm{H}=\mathrm{PhNH}_{2}, \mathrm{BuNH}_{2}$, morpholine; 61-94\%

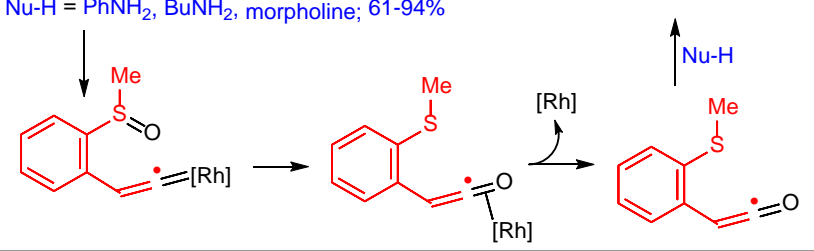

Scheme 12 Rh-catalyzed oxidative addition of nucleophiles to phenylacetylenes using internal sulfoxides as oxidant

Other internal oxidants such as pyridine $\mathrm{N}$-oxides are also effective for oxidation of Rh-vinylidenes to ketenes in the 
transformation of 3-pyridyl-1-propynes into ester or amides (Scheme 13). ${ }^{24}$

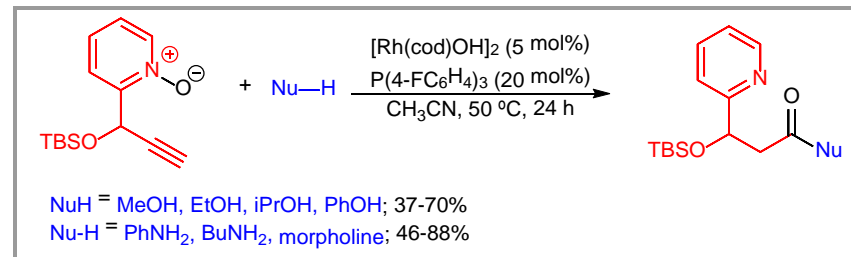

Scheme 13 Rh-catalyzed oxidative addition of nucleophiles to 3-pyridyl-1propynes using internal pyridine $\mathrm{N}$-oxide as oxidant

\subsection{2 [2+2] Cycloadditions}

Another typical transformation of ketenes is the formation of $\beta$ lactams by $[2+2]$ cycloadditions with imines. Indeed, a tandem intermolecular process leading to $\beta$-lactams via $\mathrm{Ru}(\mathrm{II})$-catalyzed oxidative transformation of terminal alkynes to ketenes by using sulfoxides as internal oxidants followed by a thermal [2+2] cycloaddition with imines was developed in 2014 (Scheme 14). ${ }^{21}$ The proposed mechanism would involve the sulfoxide oxidation of the Ru-vinylidene initially formed to the ketene followed by an intermolecular [2+2] cycloaddition with the imine to give the corresponding $\beta$-lactam.

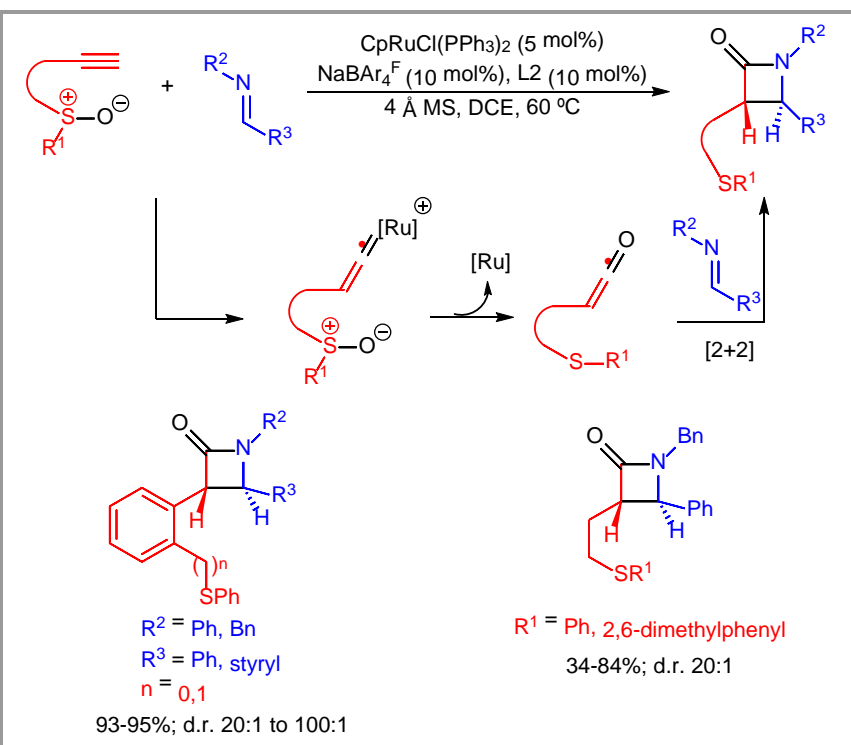

Scheme 14 Ru-catalyzed oxidative [2+2] cycloaddition of imines and alkynes to $\beta$-lactams

\section{Oxidation of Metal-Vinylidenes with External Oxidants}

In all the previous examples for the oxidation of alkynes via catalytic metal-vinylidenes, the oxidant is linked to the alkyne through a chain that allows the oxidation of the catalytic metalvinylidene initially formed. Nevertheless, some drawbacks could arise from this strategy such as difficulties for the synthesis of starting materials and/or the presence of the reduced species in the final product. In those cases, the use of an external oxidant could help to solve the trouble.

\subsection{Intramolecular Reactions}

One early example of an external oxidants for intramolecular oxidation of metal-vinylidenes for the synthesis of $\gamma$ butyrolactones and $\delta$-valerolactones from homo- and bishomopropargyl alcohols was reported, even though no ketene formation was claimed for this transformation (Scheme 15). ${ }^{23}$ The proposed mechanism would involve the formation of the Rualkoxy carbene XXVIII by intramolecular addition of the alcohol to the Ru-vinylidene species XXVII and subsequently attack by the oxidant to form XXIX. Finally, protonolysis of XXIX would afford the lactone with regeneration of the active Ru species.

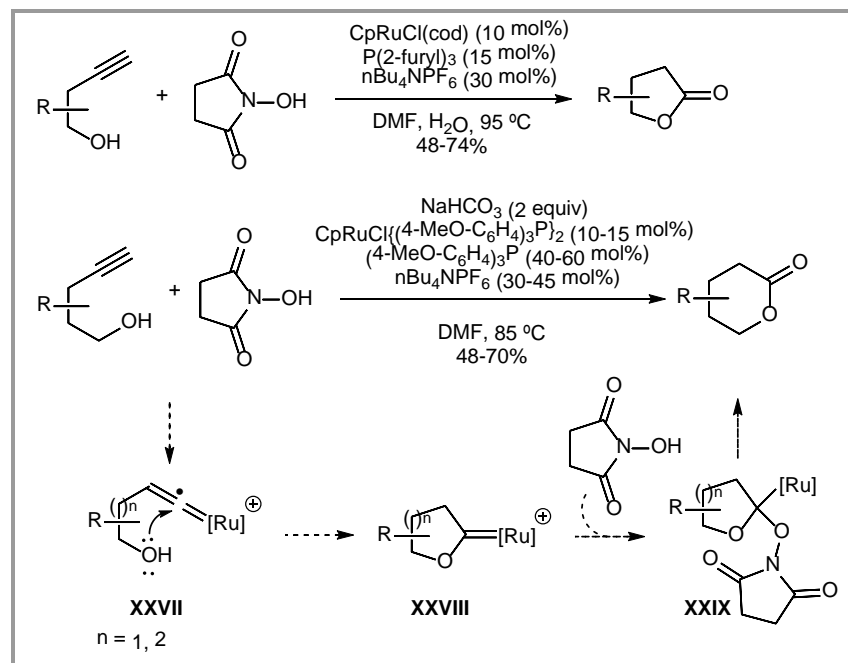

Scheme 15 Ru-catalyzed synthesis of $\gamma$-butyrolactones and $\delta$-valerolactones from homo- and bis-homopropargyl alcohols

Macrolactones can also be synthesized by a synergistic Rh-and Yb-cocatalyzed oxidative cyclization of alkynyl alcohols (Scheme 16). ${ }^{25} \alpha, \omega$-Alkynols in the presence of a catalytic amount of $\mathrm{Rh}(\operatorname{cod})_{2} \mathrm{BF}_{4}, \mathrm{Yb}(\mathrm{OTf})_{3}$ as Lewis acid, $\mathrm{P}\left(4-\mathrm{FC}_{6} \mathrm{H}_{4}\right)_{3}$ as ligand and pyridine $\mathrm{N}$-oxide as oxidant generate the corresponding macrolactones up to 33-membered in good yields. The mechanistic proposal involves the formation of a ketene by oxidation of the initially formed metal-vinylidene followed by intramolecular trapping with the alcohol. 


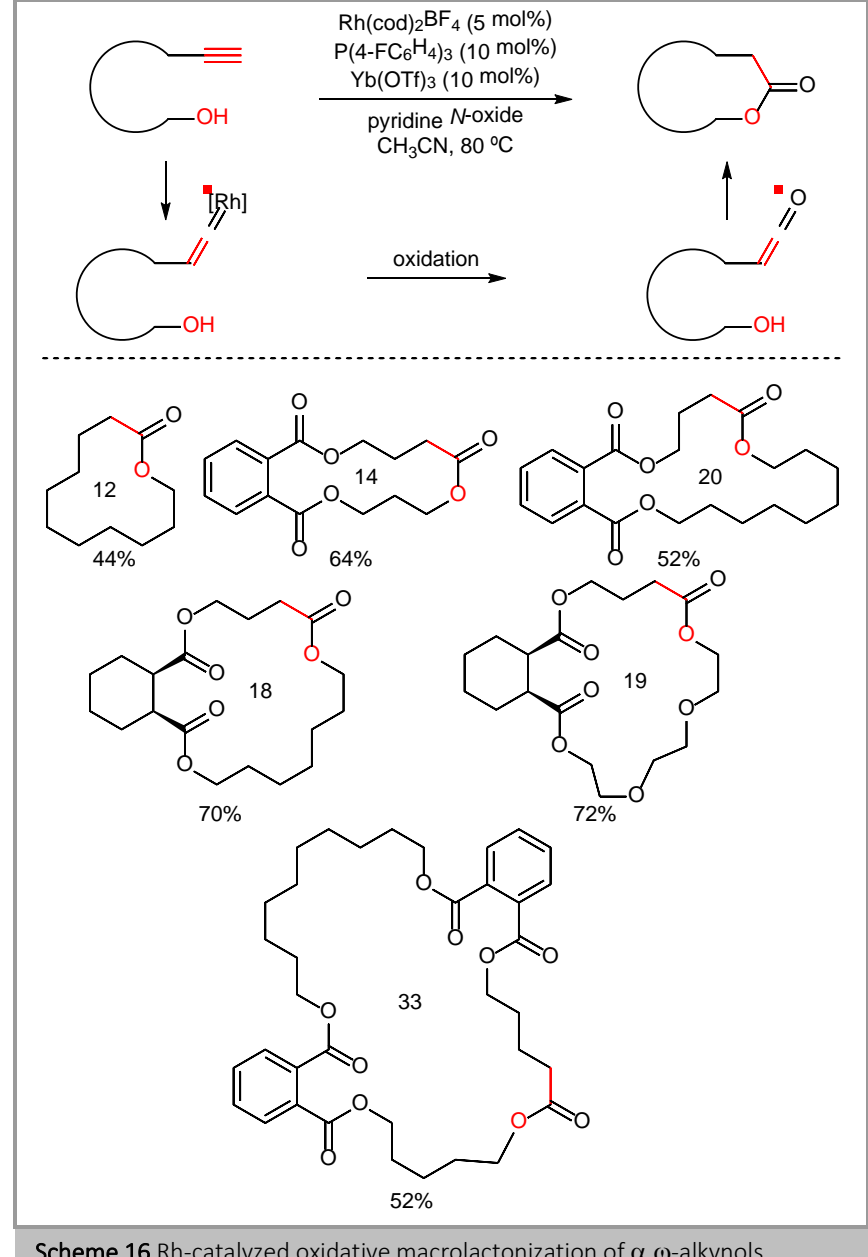

Scheme 16 Rh-catalyzed oxidative macrolactonization of $\alpha, \omega$-alkynols

On the other hand, phenols and naphthols were also assembled by Rh-catalyzed oxidative cycloaromatization of dienynes using pyridine $N$-oxide as external oxidant (Scheme 17). ${ }^{26}$ The proposed mechanism involves the formation of a dienyl-ketene intermediate followed by its $6 \mathrm{e}^{-} \pi$ electrocyclization/aromatization. The intermediate ketene could be trapped as ethyl ester derivative when ethanol was used as solvent.

oxyridine $\mathrm{N}$-oxide 2 equiv
$\mathrm{PhCl}, 100{ }^{\circ} \mathrm{C}$

Scheme 17 Rh-catalyzed oxidative cycloaromatization of dienynes to phenols

\subsection{Intermolecular Reactions}

\subsubsection{Nucleophilic Additions}

The addition of oxygen and nitrogen nucleophiles to ketenes generated by oxidation of catalytic metal-vinylidenes using external oxidants to produce esters and amides from alkynes was described as continuation of the study made using internal oxidants (see section 2.2.1). ${ }^{24}$ The main difference found in this study between internal and external oxidants was that, while in the first case both sulfoxides an $\mathrm{N}$-oxides can act as efficient oxidants to produce the corresponding products in good yields, in the latter only pyridine $\mathrm{N}$-oxides are able to oxidize the corresponding vinylidenes to ketenes and yield the corresponding esters or amides (Scheme 18). ${ }^{24}$

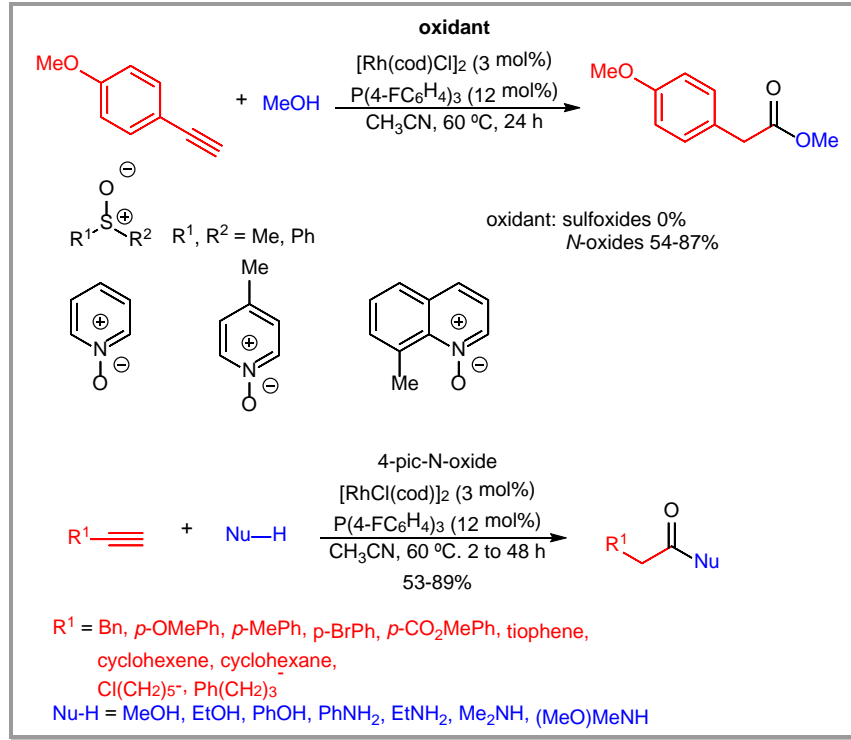

Scheme 18 Screening of external oxidants and scope for the Rh-catalyzed oxidative addition of nucleophiles to alkynes

Tandem intermolecular processes have also been developed. Coumarin skeletons were efficiently obtained by reaction of phenylacetylenes with salicylaldehydes under oxidative conditions using Wilkinson's catalyst (Scheme 19). ${ }^{27}$ The tandem process involves the generation of the phenylketene by oxidation of the initially formed Rh-vinylidene followed by nucleophilic attack of the hydroxy group of the salicylaldehyde to the ketene and subsequent intramolecular aldol-type condensation.

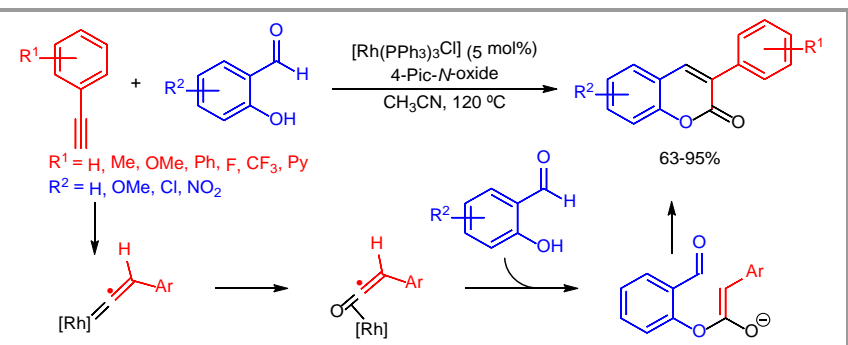

Scheme 19 Rh-catalyzed oxidative annulation of phenylacetylenes and salicylaldehydes to coumarin skeletons 
Other metals like Mn-porfirin complex, [ $\left.\mathrm{MnCl}\left(2,6-\mathrm{Cl}_{2} \mathrm{TPP}\right) \mathrm{Cl}\right]$ (meso-tetrakis(2,6-dichlorophenyl)porphyrin), and oxidants like Oxone also catalyzed the oxidative amidation of alkynes with amines (Scheme 20). ${ }^{28}$ In this case, instead of a metal-vinylidene intermediate, an oxirene is proposed as the initial species which then isomerizes to a ketene.

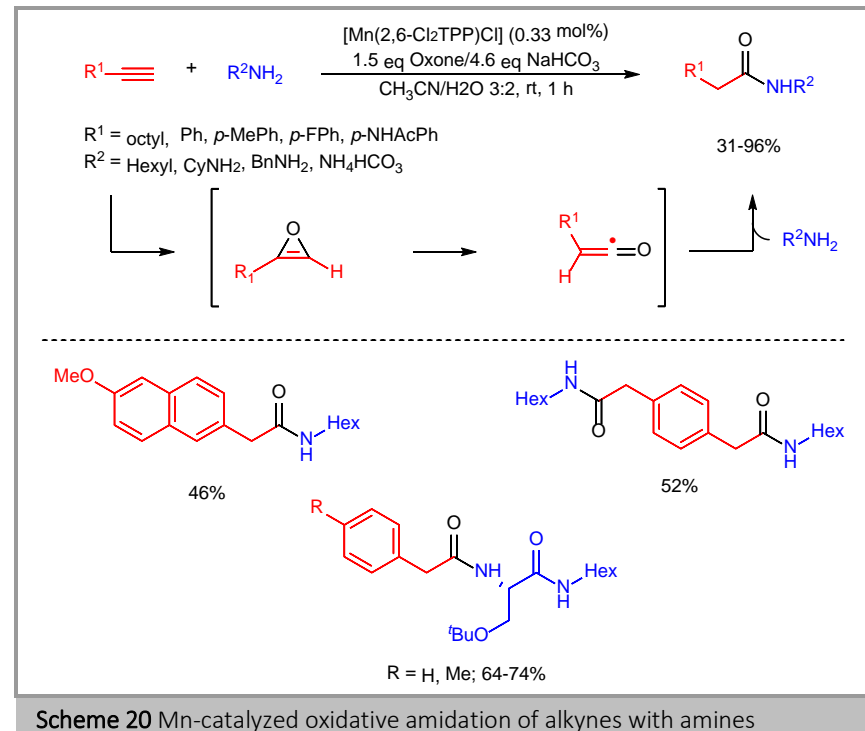

Our research group recently described the use of easily available $\mathrm{CpRuCl}\left(\mathrm{PPh}_{3}\right)_{2}$ to catalyze the oxidative amidation of alkynes with primary and secondary amines using 4-picoline $\mathrm{N}$-oxide as external oxidant, either using two or one equivalents of the free amine, being necessary, in the latest case, the use of one equivalent of $\mathrm{KPF}_{6}$ as additive. Thus, electron-poor and electronrich heteroaryl alkynes as well as aliphatic, functionalized aliphatic alkynes and enynes react with $\mathrm{N}$-Me-phenethylamine to give rise to tertiary amides in fairly good yields (Scheme 21). ${ }^{29}$ Interestingly, the use of rhodium catalysts such as $[\mathrm{Rh}(\mathrm{cod}) \mathrm{Cl}]_{2}$ or $\mathrm{RhCl}\left(\mathrm{PPh}_{3}\right)_{3}$ failed to produce the corresponding amides, being necessary the use of the ammonium salt of the $\mathrm{N}$-Mephenethylamine to yield the product in good yields. Other secondary cyclic amines and $\mathrm{N}, \mathrm{O}$-dimethylhydroxylamine also gave the corresponding amides in good yields.

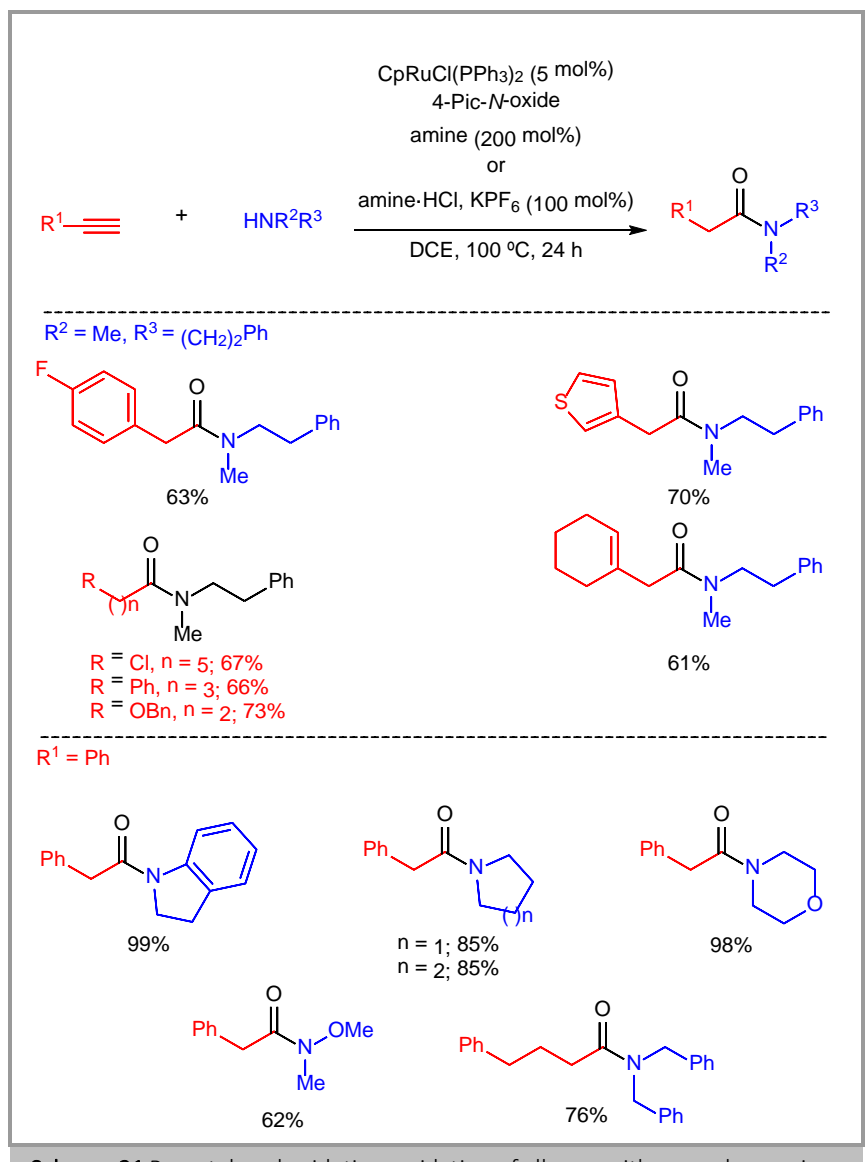

Scheme 21 Ru-catalyzed oxidative amidation of alkynes with secondary amines

More appealing secondary amides can also be achieved using this methodology. Phenylacetylene, functionalized aliphatic alkynes, enynes and aromatic diynes react with phenethylamine to yield the corresponding amides in good yields (Scheme 22). As in the case of secondary amines, Rh catalysts failed to yield the amides unless the ammonium salt of the phenethylamine was used. Other aliphatic, allylic, propargylic and aryl diamines gave the corresponding phenylacetamides in good yields. Interestingly, the use of chiral secondary amines such as (R)-1phenylethylamine gave the chiral secondary amide with excellent yields. 


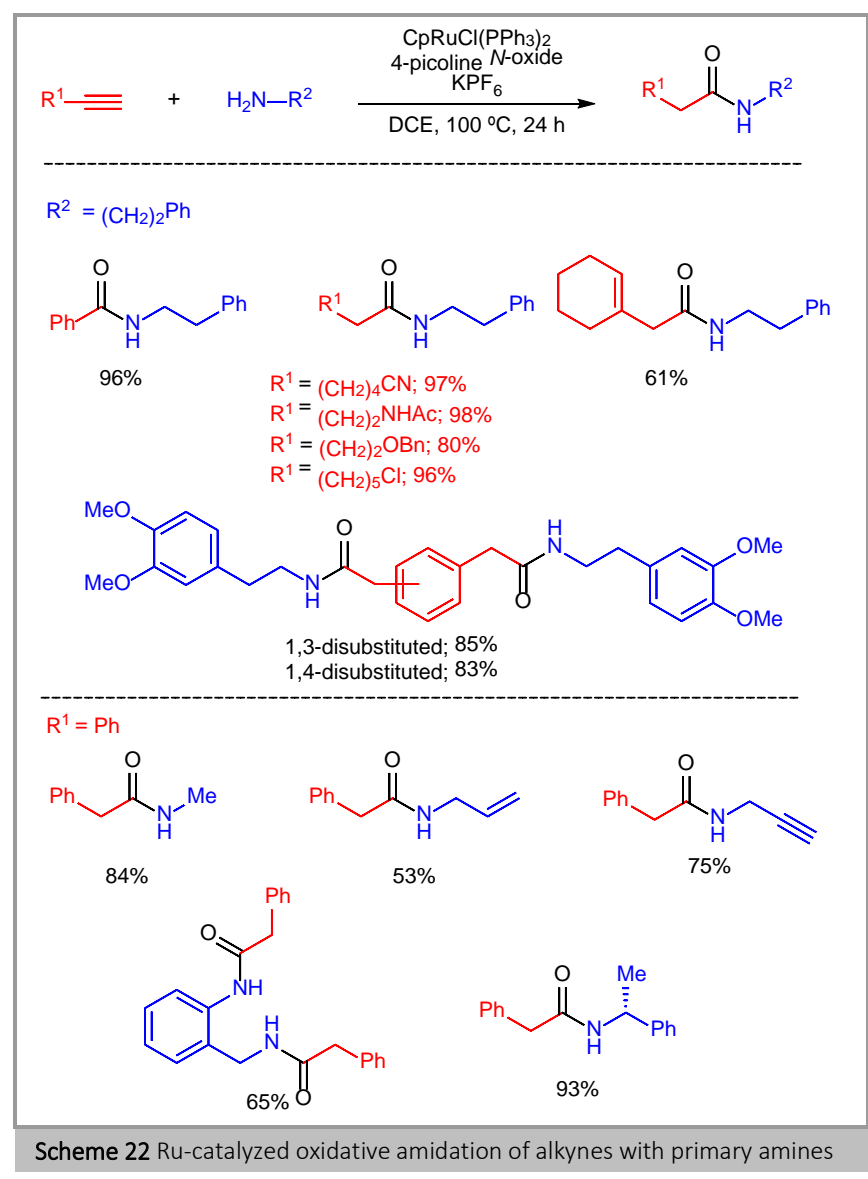

Stoichiometric experiments adding 4-picoline $\mathrm{N}$-oxide to $\mathrm{Ru}$ vinylidene $\mathbf{X X X}$ gave a mixture that contains mainly the picoline derivative $\left[\mathrm{CpRu}(4-\mathrm{Me}-\mathrm{py})\left(\mathrm{PPh}_{3}\right)_{2}\right] \mathrm{PF}_{6}$ and a $\mathrm{Ru}-\mathrm{C}(=0) \mathrm{CH}_{2} \mathrm{Ph}$ acyl species, indicating as a strong indirect evidence the oxidation of the $\mathrm{Ru}=\mathrm{C}$ bond of the vinylidene to a $\mathrm{Ru}\left(\eta^{2}-\mathrm{CO}\right)$-ketene intermediate (scheme 23).

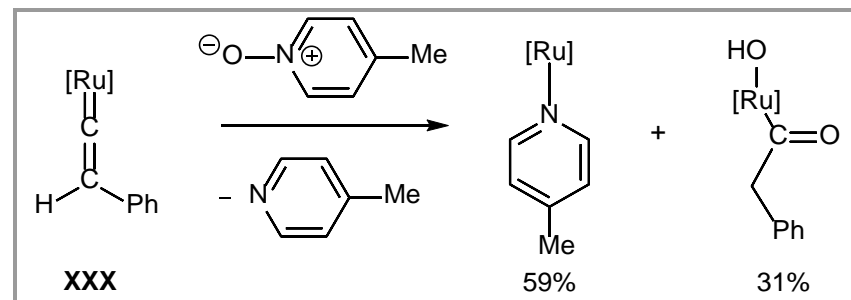

$[\mathrm{Ru}]=\left[\mathrm{CpRu}\left(\mathrm{PPh}_{3}\right)_{2}\right]^{\oplus}$

Scheme 23 Stoichiometric experiments with Ru-vinylidene species in the presence of 4-picoline $\mathrm{N}$-oxide

According to the stoichiometric results, the proposed mechanism for this transformation would involve the initial formation of the $\mathrm{Ru}$-vinylidene species $\mathbf{X X X}$ followed by its oxidation with the 4picoline $\mathrm{N}$-oxide to the $\mathrm{Ru}\left(\eta^{2}\right.$-CO)-ketene intermediate $\mathbf{X X X I}$ which, by ligand exchange, would release the ketene XXXII with concomitant formation of the Ru-picoline complex XXXIII. Final trapping of the ketene with the amines would afford the corresponding amides while ligand exchange of picoline with the alkyne would regenerate the initial Ru-vinylidene complex (Scheme 24).

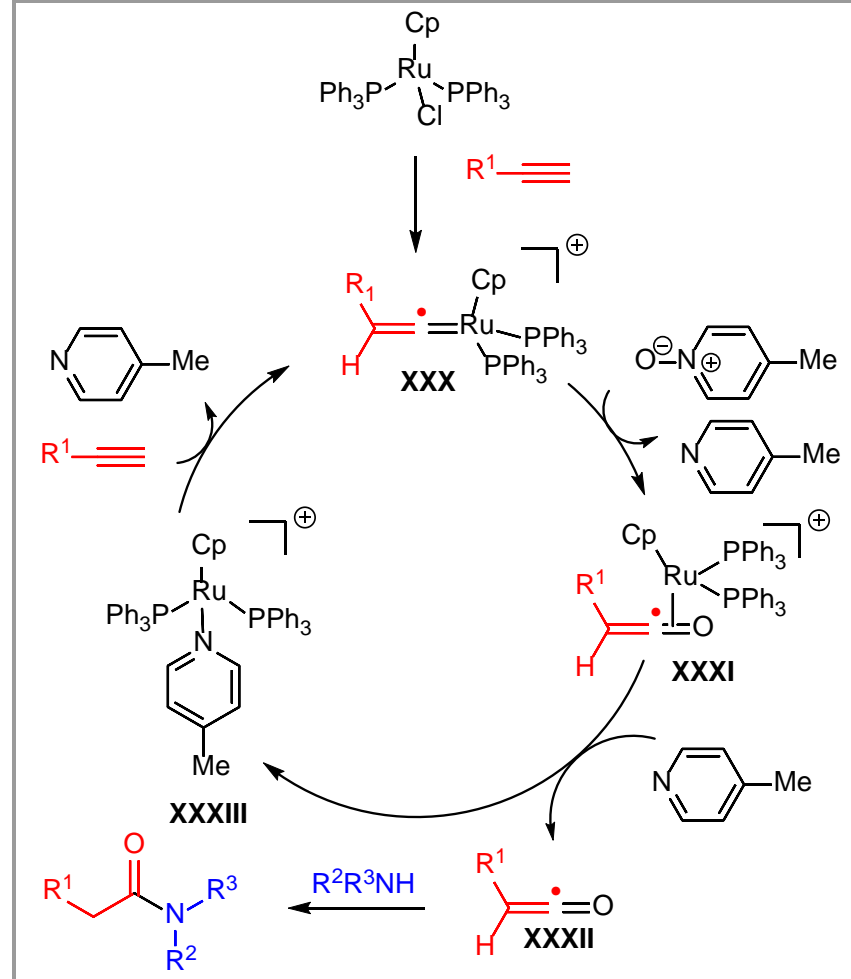

Scheme 24 Proposed mechanism for Ru-catalyzed oxidative amidation of terminal alkynes with amines

\subsection{2 [2+2] Cycloadditions}

$\beta$-Lactams with high 3,4-trans selectivity can also be assembled by intermolecular [2+2] cycloaddition of terminal alkynes and imines catalyzed by the Wilkinson's catalyst in the presence of an external oxidant like 4-picoline $N$-oxide (Scheme 25). ${ }^{30}$ The reaction showed a broad scope both with regard to the imine and alkyne substrates. Thus, aryl and heteroaryl imines with different substituents as well as alkenyl imines participate properly in the reaction. Regarding the alkyne scope, aryl, heteroaryl, alkenyl and linear alkyl substituents afforded the corresponding $\beta$ lactams in good yields. Interestingly, when alkyl substituted alkynes were used, it was necessary the addition of a $15 \mathrm{~mol} \%$ of $\mathrm{ZnCl}_{2}$ to accelerate the reaction and also to increase the yield.

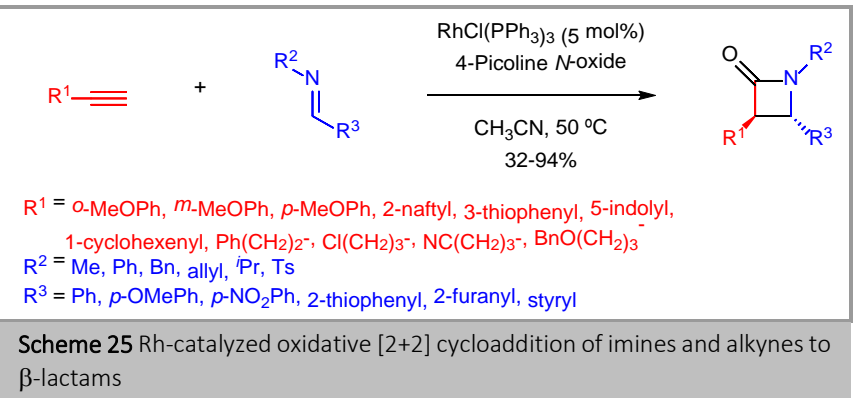

A control experiment between $p$-MeOphenylacetyl chloride and $N$-methyl- $p$-nitrophenylmethanimine under two sets of conditions was performed: when the Staudinger protocol ${ }^{31}$ was used $\left(\mathrm{Et}_{3} \mathrm{~N}, \Delta\right)$, cis $\beta$-lactam was obtained as major isomer, while in the presence of $\mathrm{RhCl}\left(\mathrm{PPh}_{3}\right)_{3}$ the trans isomer was favored, 
indicating, most probably, the presence of a Rh-ketene complex rather than a free ketene intermediate (Scheme 26).

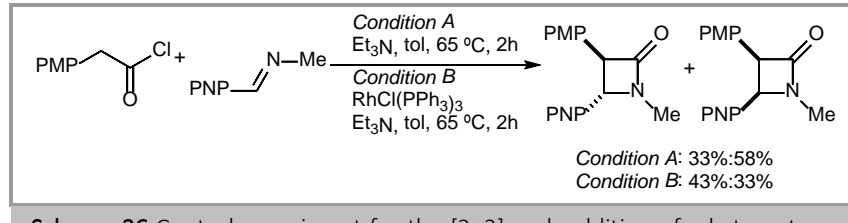

Scheme 26 Control experiment for the $[2+2]$ cycloaddition of a ketene to an imine

According to these results the proposed mechanism would involve the initial formation of the Rh-vinylidene XXXIV which, after oxidation with the 4-picoline- $N$-oxide, would afford the two $\eta^{2}$-Rh-ketene species in equilibrium XXXV and XXXVI. The nucleophilic addition of the imine to the ketene would give rise to the zwitterionic intermediates XXXVII which easily isomerize to iminium XXXVIII, given the preference for the obtention of trans $\beta$-lactam (Scheme 27).

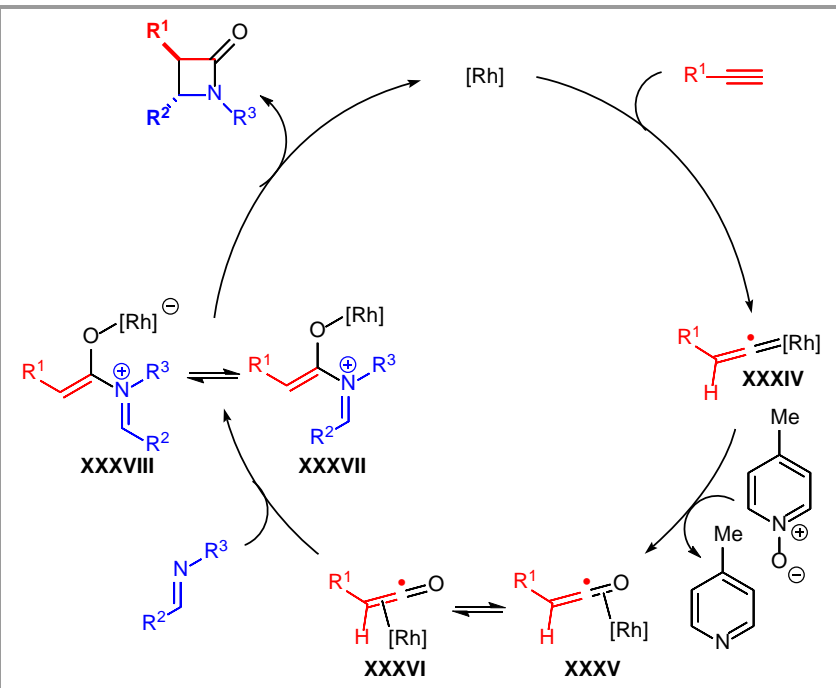

Scheme 27 Mechanistic proposal for the Rh-catalyzed oxidative $[2+2]$ cycloaddition of imines and alkynes to $\beta$-lactams

\section{Conclusions}

Recent examples of oxidative reactions of alkynes to cyclic ketones, esters, amides and lactams via catalytic $\mathrm{Rh}-$ and $\mathrm{Ru}-$ vinylidenes have been compiled. Ketenes have been invoked as intermediates from oxidation of the initially formed metalvinylidenes. Intra- and intermolecular processes such as cyclizations, [2+2] cycloadditions and nucleophilic additions have been described either using internal or external oxidants. Epoxides have been used as oxidants for intramolecular cyclizations whereas sulfoxides and pyridine $\mathrm{N}$-oxides for [2+2] cycloadditions and nucleophile additions, although sulfoxides have shown only activity when they act as internal oxidants while $\mathrm{N}$-oxides have probed to be more versatile oxidants either internally or externally. These initial examples show the high potential of the transformations of simple alkynes into a variety of functionalized compounds with increased complexity. Nevertheless, more mechanistic studies are needed to fully understand this transformation in order to increase its scope.

\section{Funding Information}

This work has received financial support from MINECO (project CTQ2017-87939R and ORFEO-CINQA network RED2018-102387-T), the Xunta de Galicia (project ED431C 2018/04 and Centro singular de investigación de Galicia accreditation 2019-2022, ED431G 2019/03) and the European Union (European Regional Development Fund - ERDF)

\section{Acknowledgment}

A.Á.-P thanks the Spanish MICINN for a predoctoral FPI fellowship.

\section{References}

(1) Ervin, K. M.; Gronert, S.; Barlow, S. E.; Gilles, M. K.; Harrison, A. G.; Bierbaum, V. M.; DePuy, C. H.; Lineberger, W. C.; Ellison, G. B. J. Am. Chem. Soc. 1990, 112, 5750.

(2) (a) Bruce, M. I. Chem. Rev. 1998, 98, 2797. (b) Bruce, M. I. Chem. Rev. 1991, 91, 197. (c) Davies, S. G.; McNally, J. P.; Smallridge, A. J. Adv. Organomet. Chem. 1990, 30, 1. (d) Antonova, A. B.; Ioganson, A. A. Russ. Chem. Rev. 1989, 58, 1197. (e) Bruce, M. I.; Swincer, A. G. Adv. Organomet. Chem. 1983, 22, 59.

(3) (a) King, R. B.; Saran, M. S. J. Chem. Soc., Chem. Commun. 1972, 1053. (b) Mills, O. S.; Redhouse, A. D. J. Chem. Soc., A 1968, 1282. (c) Mills, O. S.; Redhouse, A. D. Chem. Commun. 1966, 444.

(4) (a) Otsuka, M.; Tsuchida, N.; Ikeda, Y.; Lambert, N.; Nakamura, R.; Mutoh, Y.; Ishii, Y.; Takano, K. Organometallics 2015, 34, 3934. (b) Jiménez-Tenorio, M.; Puerta, M. C.; Valerga, P.; Ortuño, M. A.; Ujaque, G.; Lledós, A. Inorg. Chem. 2013, 52, 8919. (c) Wang, Q.; Wang, X.; Andrews, L. J. Phys. Chem. A 2011, 115, 12194. (d) Swennenhuis, B. H. G.; Benjamin Cieslinski, G.; Brothers, E. N.; Bengali, A. A. J. Organomet. Chem. 2010, 695, 891. (e) Lynam, J. M. Chem. Eur. J. 2010, 16, 8238. (f) Cadierno, V.; Gamasa, M. P.; Gimeno, J. Coord. Chem. Rev. 2004, 248, 1627. (g) Wakatsuki, Y. J. Organomet. Chem. 2004, 689, 4092. (h) Puerta, M. C.; Valerga, P. Coord. Chem. Rev. 1999, 193-195, 977.

(5) (a) Bassetti, M.; Cadierno, V.; Gimeno, J.; Pasquini, C. Organometallics 2008, 27, 5009. (b) De Angelis, F.; Sgamellotti, A.; Re, N. Organometallics 2002, 21, 2715. (c) De Angelis, F.; Sgamellotti, A.; Re, N. Organometallics 2002, 21, 5944. (d) Tokunaga, M.; Suzuki, T.; Koga, N.; Fukushima, T.; Horiuchi, A.; Wakatsuki, Y. J. Am. Chem. Soc. 2001, 123, 11917. (e) Wakatsuki, Y.; Koga, N.; Yamazaki, H.; Morokuma, K. J. Am. Chem. Soc. 1994, 116, 8105.

(6) (a) Vastine, B. A.; Hall, M. B. Organometallics 2008, 27, 4325. (b) Grotjahn, D. B.; Zeng, X.; Cooksy, A. L.; Kassel, W. S.; DiPasquale, A. G.; Zakharov, L. N.; Rheingold, A. L. Organometallics 2007, 26, 3385. (c) De Angelis, F.; Sgamellotti, A.; Re, N. Organometallics 2007, 26, 5285. (d) Grotjahn, D. B.; Zeng, X.; Cooksy, A. L. J. Am. Chem. Soc. 2006, 128, 2798. (e) Pérez-Carreño, E.; Paoli, P.; Ienco, A.; Mealli, C. Eur. J. Inorg. Chem. 1999, 1315. (f) Wakatsuki, Y.; Koga, N.; Werner, H.; Morokuma, K. J. Am. Chem. Soc. 1997, 119, 360.

(7) Oliván, M.; Clot, E.; Eisenstein, O.; Caulton, K. G. Organometallics 1998, 17, 3091.

(8) (a) Lass, R. W.; Werner, H. Inorg. Chim. Acta 2011, 369, 288. (b) Konkol, M.; Steinborn, D. J. Organomet. Chem. 2006, 691, 2839. (c) Ilg, K.; Paneque, M.; Poveda, M. L.; Rendón, N.; Santos, L. L.; Carmona, E.; Mereiter, K. Organometallics 2006, 25, 2230. (d) Jiménez, M. V.; Sola, E.; Lahoz, F. J.; Oro, L. A. Organometallics 2005, 24, 2722. (e) Murakami, M.; Hori, S. J. Am. Chem. Soc. 2003, 125, 4720. (f) Foerstner, J.; Kakoschke, A.; Goddard, R.; 
Rust, J.; Wartchow, R.; Butenschön, H. J. Organomet. Chem. 2001, 617-618, 412. (g) Huang, D.; Streib, W. E.; Eisenstein, O.; Caulton, K. G. Organometallics 2000, 19, 1967. (h) Katayama, H.; Ozawa, F. Organometallics 1998, 17, 5190. (i) Werner, H.; Lass, R. W.; Gevert, O.; Wolf, J. Organometallics 1997, 16, 4077. (j) Katayama, H.; Onitsuka, K.; Ozawa, F. Organometallics 1996, 15, 4642. (k) Onitsuka, K.; Katayama, H.; Sonogashira, K.; Ozawa, F. J. Chem. Soc., Chem. Commun. 1995, 2267. (l) Connelly, N. G.; Geiger, W. E.; Lagunas, C.; Metz, B.; Rieger, A. L.; Rieger, P. H.; Shaw, M. J. J. Am. Chem. Soc. 1995, 117, 12202. (m) Naka, A.; Okazaki, S.; Hayashi, M.; Ishikawa, M. J. Organomet. Chem. 1995, 499, 35. (n) Werner, H.; Baum, M.; Schneider, D.; Windmüller, B. Organometallics 1994, 13, 1089. (o) Sakurai, H.; Fujii, T.; Sakamoto, K. Chem. Lett. 1992, 339. (p) Schneider, D.; Werner, H. Angew. Chem., Int. Ed. Engl. 1991, 30, 700.

(9) (a) Venkatesan, K.; Fox, T.; Schmalle, H. W.; Berke, H. Eur. J. Inorg. Chem. 2005, 2005, 901. (b) Venkatesan, K.; Blacque, O.; Fox, T.; Alfonso, M.; Schmalle, H. W.; Kheradmandan, S.; Berke, H. Organometallics 2005, 24, 920.

(10) Miller, D. C.; Angelici, R. J. Organometallics 1991, 10, 79.

(11) (a) Miura, T.; Murata, H.; Kiyota, K.; Kusama, H.; Iwasawa, N.J. Mol. Catal. A 2004, 213, 59. (b) Miura, T.; Murata, H.; Kiyota, K.; Kusama, H.; Iwasawa, N. J. Mol. Catal. A: Chem. 2004, 213, 59. (c) Miura, T.; Iwasawa, N. J. Am. Chem. Soc. 2002, 124, 518. (d) Löwe, C.; Hund, H.-U.; Berke, H. J. Organomet. Chem. 1989, 371 , 311.

(12) (a) Otsuka, M.; Tsuchida, N.; Ikeda, Y.; Kimura, Y.; Mutoh, Y.; Ishii, Y.; Takano, K. J. Am. Chem. Soc. 2012, 134, 17746. (b) Mutoh, Y.; Kimura, Y.; Ikeda, Y.; Tsuchida, N.; Takano, K.; Ishii, Y. Organometallics 2012, 31, 5150. (c) Mutoh, Y.; Imai, K.; Kimura, Y.; Ikeda, Y.; Ishii, Y. Organometallics 2011, 30, 204. (d) Singh, V. K.; Bustelo, E.; de los Ríos, I.; Macías-Arce, I.; Puerta, M. C.; Valerga, P.; Ortuño, M. A.; Ujaque, G.; Lledós, A. Organometallics 2011, 30, 4014. (e) de los Ríos, I.; Bustelo, E.; Puerta, M. C.; Valerga, P. Organometallics 2010, 29, 1740. (f) Mutoh, Y.; Ikeda, Y.; Kimura, Y.; Ishii, Y. Chem. Lett. 2009, 38, 534. (g) Ikeda, Y.; Yamaguchi, T.; Kanao, K.; Kimura, K.; Kamimura, S.; Mutoh, Y.; Tanabe, Y.; Ishii, Y. J. Am. Chem. Soc. 2008, 130, 16856. (h) Shaw, M. J.; Bryant, S. W.; Rath, N. Eur. J. Inorg. Chem. 2007, 3943.

(13) (a) Roh, S. W.; Choi, K.; Lee, C. Chem. Rev. 2019, 119, 4293. (b) Varela, J. A.; González-Rodríguez, C.; Saá, C. Top. in Organomet. Chem. 2014, 48, 237. (c) Lozano-Vila, A. M.; Monsaert, S.; Bajek, A.; Verpoort, F. Chem. Rev. 2010, 110, 4865. (d) Trost, B. M.; McClory, A. Chem. Asian J. 2008, 3, 164. (e)
Varela, J. A.; González-Rodríguez, C.; Rubín, S. G.; Castedo, L.; Saá, C. Pure Appl. Chem. 2008, 80, 1167. (f) Liu, R.-S. Synlett 2008, 801. (g) Bruneau, C.; Dixneuf, P. H. Angew. Chem. Int. Ed. 2006, 45, 2176. (h) Varela, J. A.; Saá, C. Chem. Eur. J. 2006, 12 , 6450. (i) Bruneau, C. Top. Organomet. Chem. 2004, 11, 125. (j) Dragutan, V.; Dragutan, I. Platinum Met. Rev. 2004, 48, 148. (k) Katayama, H.; Ozawa, F. Coord. Chem. Rev. 2004, 248, 1703. (l) Bruneau, C.; Dixneuf, P. H. Acc. Chem. Res. 1999, 32, 311.

(14) (a) Xu, Z.; Chen, H.; Wang, Z.; Ying, A.; Zhang, L. J. Am. Chem. Soc. 2016, 138, 5515. (b) Yeom, H.-S.; Shin, S. Acc. Chem. Res. 2014, 47, 966.

(15) Allen, A. D.; Tidwell, T. T. Eur. J. Org. Chem. 2012, 2012, 1081.

(16) (a) Kandler, H.; Bidell, W.; Jaenicke, M.; Knickmeier, M.; Veghini, D.; Berke, H. Organometallics 1998, 17, 960. (b) Grotjahn, D. B.; Lo, H. C. Organometallics 1995, 14, 5463.

(17) Madhushaw, R. J.; Lin, M.-Y.; Sohel, S. M. A.; Liu, R.-S. J. Am. Chem. Soc. 2004, 126, 6895.

(18) Lin, M.-Y.; Madhushaw, R. J.; Liu, R.-S. J. Org. Chem. 2004, 69, 7700.

(19) Lin, M.-Y.; Maddirala, S. J.; Liu, R.-S. Org. Lett. 2005, 7, 1745.

(20) Pati, K.; Liu, R.-S. Chem. Commun. 2009, 5233.

(21) Wang, Y.; Zheng, Z.; Zhang, L. Angew. Chem. Int. Ed. 2014, 53, 9572.

(22) (a) Kang, X.; Zuckerman, N. B.; Konopelski, J. P.; Chen, S. J. Am. Chem. Soc. 2012, 134, 1412. (b) Ávarez, P.; Lastra, E.; Gimeno, J.; Bassetti, M.; Falvello, L. R. J. Am. Chem. Soc. 2003, 125, 2386.

(23) (a) Trost, B. M.; Rhee, Y. H. J. Am. Chem. Soc. 2002, 124, 2528. (b) Trost, B. M.; Rhee, Y. H. J. Am. Chem. Soc. 1999, 121, 11680.

(24) Kim, I.; Lee, C. Angew. Chem. Int. Ed. 2013, 52, 10023.

(25) Zhang, W.-W.; Gao, T.-T.; Xu, L.-J.; Li, B.-J. Org. Lett. 2018, 20,6534 .

(26) Rong, M.-G.; Qin, T.-Z.; Liu, X.-R.; Wang, H.-F.; Zi, W. Org. Lett. 2018, 20, 6289.

(27) Zeng, H.; Li, C.-J. Angew. Chem. Int. Ed. 2014, 53, 13862.

(28) Chan, W.-K.; Ho, C.-M.; Wong, M.-K.; Che, C.-M. J. Am. Chem. Soc. 2006, 128, 14796.

(29) Álvarez-Pérez, A.; Esteruelas, M. A.; Izquierdo, S.; Varela, J. A.; Saá, C. Org. Lett. 2019, 21, 5346.

(30) Kim, I.; Roh, S. W.; Lee, D. G.; Lee, C. Org. Lett. 2014, 16, 2482.

(31) Li, B.; Wang, Y.; Du, D.-M.; Xu, J.J. Org. Chem. 2007, 72, 990. 


\section{Biosketches}

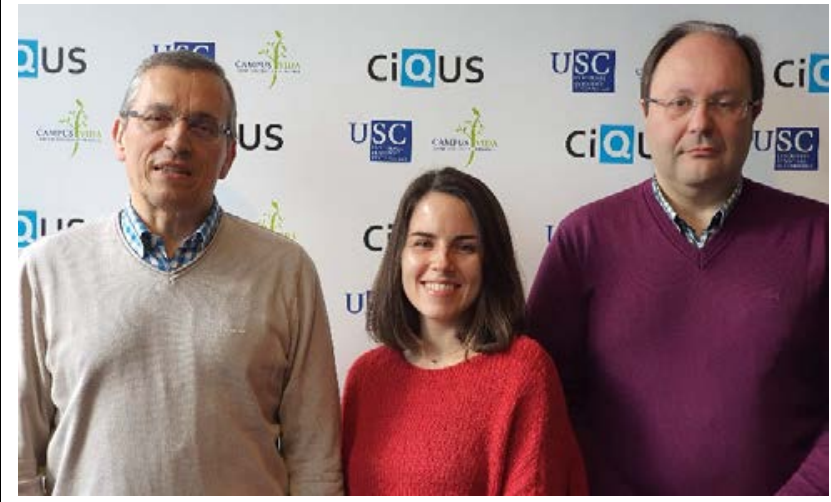

Jesús A. Varela (right) born in Lugo, Spain, and studied chemistry at the Universidad de Santiago de Compostela, Spain. After a predoctoral research training period in Harvard University under supervision of Prof. Dr. Matthew Shair, he completed his Ph. D. thesis in 1999 (excellent award) under the supervision of Prof. Dr. Carlos Saá for research on synthesis of oligopyridines via cobalt chemistry. From 1999 to 2001, he spent a postdoctoral period as an Alexander Von Humboldt and Marie Curie Fellow with Prof. Dr. Paul Knochel at Ludwig Maximilians Universität in Munich (Germany), working on remote $\mathrm{C}-\mathrm{H}$ activation via hydroboration. After that, he joined the faculty at the Universidad de Santiago de Compostela as Ramón y Cajal researcher, and since 2008 as Profesor Titular. His research interests are focused in organometallic catalysis towards the synthesis of biological active systems or molecular materials and its mechanistic study

Carlos Saá (left) born in Lugo (Spain), studied chemistry at the Universidad de Santiago de Compostela (Spain) where he received his PhD in 1985 under the supervision of Profs. L. Castedo, R. Suau and J. M. Saá. He spent two-year (1987-1988) as a NATO postdoctoral research associate at the University of California, Berkeley, working with Prof. K. P. C. Vollhardt in a Cobalt catalytic approach to ergot alkaloids. In 1990, he joined the faculty at the Universidad de Santiago de Compostela as Profesor Titular, and since 2004 has been a full Professor. His research interest centers on the discovery of new methodology of organometallic catalysis and their applications to the synthesis of bioactive compounds and organic conductive materials.

Andrea Álvarez-Pérez (middle) received her B.Sc. degree in Chemistry from the University of Santiago de Compostela in 2013. Then, she also obtained the M.Sc. in Advanced Chemistry from the same university in 2014 under the supervision of Prof. Carlos Saá and Prof. Jesús A. Varela. After a short research stay in Cambridge working on palladium(II)-catalyzed carbonylation reactions under the supervision of Matthew J. Gaunt in 2016, she got her PhD in Organic Chemistry in 2019 under the supervision of Prof. Carlos Saá and Prof. Jesús A. Varela for research on metal-catalyzed intramolecular hydroaminations and oxidative amidations of alkynes. Her research interests include the development of new catalytic transformations and his application in the synthesis of valuable $N$-heterocycles. 